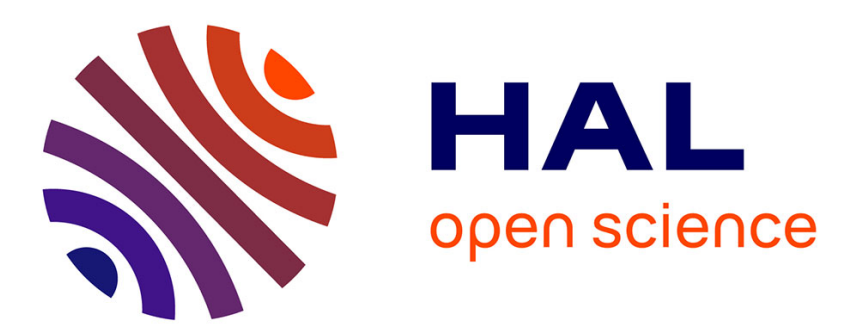

\title{
Formation dynamics of sand bedforms under solitons and bound states of solitons in a wave flume used in resonant mode
}

François Marin, Alexander Ezersky

\section{- To cite this version:}

François Marin, Alexander Ezersky. Formation dynamics of sand bedforms under solitons and bound states of solitons in a wave flume used in resonant mode. European Journal of Mechanics - B/Fluids, 2008, 27 (3), pp.251-267. 10.1016/j.euromechflu.2007.05.003 . hal-02095167

\section{HAL Id: hal-02095167 \\ https://hal.science/hal-02095167}

Submitted on 10 Apr 2019

HAL is a multi-disciplinary open access archive for the deposit and dissemination of scientific research documents, whether they are published or not. The documents may come from teaching and research institutions in France or abroad, or from public or private research centers.
L'archive ouverte pluridisciplinaire HAL, est destinée au dépôt et à la diffusion de documents scientifiques de niveau recherche, publiés ou non, émanant des établissements d'enseignement et de recherche français ou étrangers, des laboratoires publics ou privés. 


\title{
Formation dynamics of sand bedforms under solitons and bound states of solitons in a wave flume used in resonant mode
}

\author{
François Marin ${ }^{\mathrm{a}, *}$, Alexander B. Ezersky ${ }^{\mathrm{b}}$ \\ ${ }^{\mathrm{a}}$ Laboratoire de Mécanique, Physique et Géosciences, Université du Havre, Place R. Schuman, B.P. 4006, 76610 Le Havre, France \\ ${ }^{\mathrm{b}}$ Laboratoire Morphodynamique Continentale et Côtière, UMR-CNRS 6143, Université de Caen, 2-4 rue des tilleuls, 14000 Caen, France
}

Received 20 October 2006; received in revised form 12 February 2007; accepted 14 May 2007

\begin{abstract}
This paper reports the results of an experimental study of the formation of sand bedforms under solitons and bound states of solitons in a wave flume used in resonant mode. A numerical modeling of Boussinesq equations is carried out to simulate the generated flow and a good agreement is obtained between the measured and calculated fluid velocities. An original method based on image processing is developed to obtain the morphology of the sandy bed over large areas. The size and the shape of ripples which form on the bed significantly change from one end of the flume to the other end. Accretion zones are observed beneath the nodes of the standing harmonic wave. These bed features result from the variation of the amplitude of the first harmonic of fluid velocity, and of the time interval between the passage of contra-propagative solitons and bound states of solitons, with the distance from the wave paddle along the flume. An equation obtained from a phenomenological analysis is proposed for the description of the temporal growth of the ripples.
\end{abstract}

(C) 2007 Published by Elsevier Masson SAS.

Keywords: Sand bedforms; Ripple formation; Hydrodynamic solitons

\section{Introduction}

Water waves over a bed of sand often generate small scale bedforms known as ripples. These bedforms strongly affect the sediment transport, the wave damping and the dispersion of pollutants. Numerous studies have been carried out on ripple formation under linear or weakly nonlinear waves (see, for instance, [1-7]). However, waves may be highly nonlinear. Long waves such as tsunamis often behave like solitary waves [8,9], highly nonlinear waves. In other respects, it is well known that as an oscillatory wave moves into shoaling water, the wave amplitude becomes higher, the trough becomes flatter, and the surface profile approaches the solitary waveform before wave breaking [10]. Boussinesq [11] performed pioneering theoretical studies of solitary waves. Korteweg and de Vries [12] derived a model equation which describes the unidirectional propagation of long waves in water of relatively shallow depth. This equation is known as the Korteweg-de Vries equation or KdV equation. The first observations and experiments on solitary waves are attributed to Russell [13,14]. Recently, Ezersky et al. [15] presented an original method to generate

\footnotetext{
* Corresponding author. Tel.: +3323274 49 70; fax: +33232744671.
}

E-mail address: francois.marin@univ-lehavre.fr (F. Marin). 
solitary waves in shallow water in a wave flume used in resonant mode. This method is used in the present study and contra-propagative solitary waves are excited on the background of a standing harmonic wave. The spatiotemporal properties of these solitary waves were investigated in [16]. From one to four pulses propagating in each direction of the flume may be generated on the time period of the flow, depending on the frequency and the amplitude of horizontal displacement of the oscillating paddle. These pulses were identified as solitons (one pulse) and bound states of solitons (several pulses) [16]. To the authors' knowledge, the only study on ripple formation induced by solitons was carried out by Marin et al. [17]. In this study, it was shown that a strong interaction between the bed and the free surface occurs. Only the case of the generation of one pulse on the time period of the flow was considered. No specific instrumentation was used to measure the ripple dimensions, and only the values of the ripple lengths and heights horizontally averaged over the flume length were estimated, directly through the glass side walls of the flume. However, present tests show that the ripple dimensions significantly vary along the flume when solitons are generated in a hydrodynamic resonator, at the equilibrium state as well as during the ripple formation. When ripples are formed in a wave flume under Stokes waves, local variations of their length and height appear as ripple patterns are never perfectly regular; this led Jarno-Druaux et al. [7] to use a statistical approach for their description. Nevertheless, at any given time during the ripple formation, the mean ripple dimensions, averaged over a sufficient number of ripples, do not significantly change from one end of the flume to the other end. This is a significant difference compare to the case of ripple formation under solitons. The aim of the present work is to specify the physical processes which govern the generation of bedforms under solitons and bound states of solitons in a wave flume used in resonant mode. An original experimental method based on image processing is developed at this aim, allowing to obtain the three dimensional morphology of the sandy bed over large areas. A numerical simulation of Boussinesq equations is carried out, and the measured and calculated fluid velocities are compared.

The structure of the paper is as follows: in Section 2, the experimental set-up and the image processing technique are presented. Section 3 which is split into three sections shows the results. The representation of solitons and bound states of solitons is described in Section 3.1. Sections 3.2 and 3.3 are devoted to the formation of ripples and accretion zones, respectively. In Section 4, a discussion is presented. The conclusions are stated in Section 5.

\section{Experimental set-up and image processing technique}

\subsection{Experimental set-up}

The tests have been carried out in a 10-m-long and 0.49-m-wide wave flume at Le Havre University (France). The mean water depth at rest was $d=0.26 \mathrm{~m}$. Surface waves are produced by an oscillating paddle at one end of the flume; a near perfect reflection takes place at the other end. The flume is used in resonant mode, without an absorbing beach. The frequency $f$ of the oscillating paddle is chosen close to the resonant frequency $f_{\mathrm{r}}=0.166 \mathrm{~Hz}$ of the mode whose wavelength is equal to the flume length. In other words, the wavelength $L_{\mathrm{h}}$ of the standing harmonic wave equals the effective flume length $L_{\mathrm{e}}\left(9.63 \mathrm{~m}\right.$; Fig. 1(a)). The ratio $d / L_{\mathrm{h}}=0.027$ lies in the range where the theory of very long shallow water waves is valid, and the harmonic wave speed is $V_{0}=\sqrt{g d}$, where $g$ is the acceleration due to gravity. For values of the amplitude of horizontal displacement of the oscillating paddle averaged over depth $a_{\mathrm{h}}$ lower than 2 $\mathrm{cm}$, only standing harmonic waves are generated in the flume. For values of $a_{\mathrm{h}}$ greater than $2 \mathrm{~cm}$, pulses propagating from one end of the channel to the other end are excited on the background of the standing harmonic wave [16]. The generation of solitons in the flume results from the excitation of higher harmonics. In the present study, the values of the frequency $f$ and of the amplitude $a_{\mathrm{h}}$ are chosen such as one or two pulses propagate in each direction of the flume on the time period of the flow (Table 1). In no test did wave breaking occur in the flume.

The instantaneous free surface elevation is measured with one resistive probe located at the reflective end of the flume (Fig. 1(a)). The acquisition frequency is $100 \mathrm{~Hz}$. The test conditions are shown in Table 1, where $A_{0}$ is the harmonic wave amplitude. In the case of the generation of one pulse on the time period of the flow, $A_{\mathrm{S} 1}$ is the soliton amplitude and $\varphi_{\mathrm{S} 1}$ is the phase shift between the soliton and the harmonic wave (Fig. 3(b) in Section 3.1 where $\Delta \tau_{\mathrm{S} 1}$ is the time interval between the passage of the soliton and the rising front of the harmonic wave; $\varphi_{\mathrm{S} 1}=\Delta \tau_{\mathrm{S} 1} \omega, \omega=2 \pi f$ being the angular frequency of the flow). When two pulses are produced, $A_{\mathrm{S} 1}$ and $A_{\mathrm{S} 2}$ are the amplitudes of the first (the highest) and of the second pulse, respectively, and $\varphi_{\mathrm{S} 1}$ and $\varphi_{\mathrm{S} 2}$ are the phase shifts between these pulses and the harmonic wave (Fig. 4(b) in Section 3.1 where $\Delta \tau_{\mathrm{S} 2}$ is the time interval between the passage of the rising front of the harmonic wave and the second pulse; $\left.\varphi_{\mathrm{S} 2}=-\Delta \tau_{\mathrm{S} 2} \omega\right)$. For Tests 1 to 5 , the bed was initially flat and covered by a 
(a)

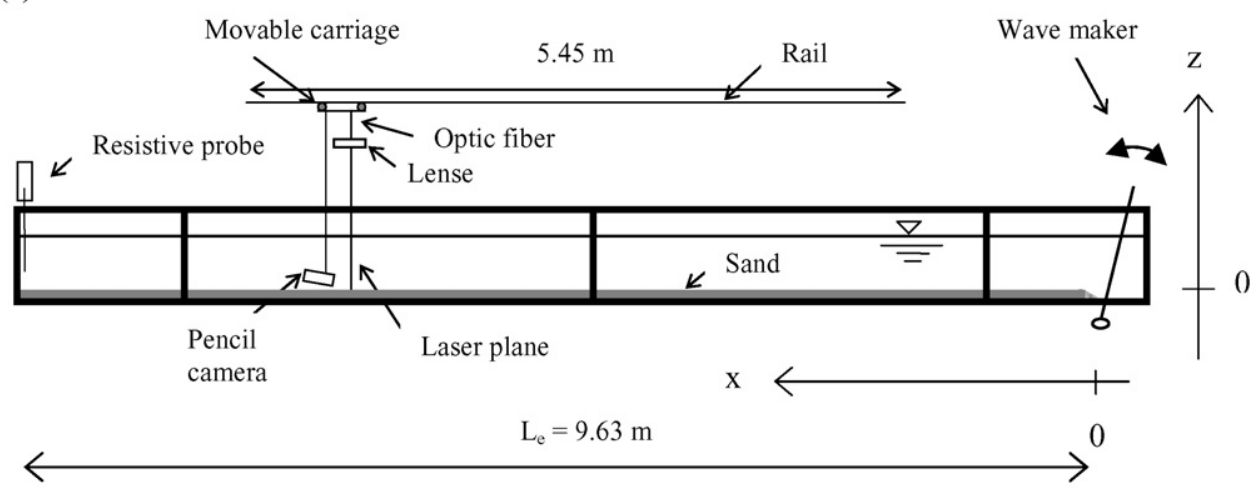

(b)
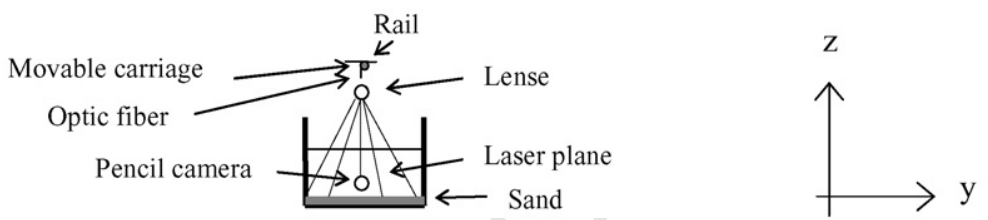

Fig. 1. (a) Side and (b) cross view of the flume.

Table 1

Test conditions

\begin{tabular}{|c|c|c|c|c|c|c|c|c|}
\hline $\begin{array}{l}\text { Test } \\
\text { number }\end{array}$ & $\begin{array}{l}f \\
(\mathrm{~Hz})\end{array}$ & $\begin{array}{l}a_{\mathrm{h}} \\
(\mathrm{cm})\end{array}$ & $\begin{array}{l}A_{\mathrm{S} 1} \text { at the } \\
\text { beginning } \\
\text { of the test } \\
(\mathrm{mm})\end{array}$ & $\begin{array}{l}A_{\mathrm{S} 2} \text { at the } \\
\text { beginning } \\
\text { of the test } \\
(\mathrm{mm})\end{array}$ & $\begin{array}{l}\varphi_{\mathrm{S} 1} \text { at the } \\
\text { beginning } \\
\text { of the test } \\
\text { (rad) }\end{array}$ & $\begin{array}{l}\varphi_{\mathrm{S} 2} \text { at the } \\
\text { beginning } \\
\text { of the test } \\
\text { (rad) }\end{array}$ & $\begin{array}{l}A_{0} \text { at the } \\
\text { beginning } \\
\text { of the test } \\
(\mathrm{mm})\end{array}$ & $\begin{array}{l}\text { Number of } \\
\text { pulses on } \\
\text { the time } \\
\text { period of } \\
\text { the flow }\end{array}$ \\
\hline 1 & 0.172 & 7.5 & 70.9 & - & 0.82 & - & 5.1 & 1 \\
\hline 2 & 0.173 & 6.5 & 75.3 & - & 0.91 & - & 5.3 & 1 \\
\hline 3 & 0.173 & 6 & 70.3 & - & 1.07 & - & 5.2 & 1 \\
\hline 4 & 0.165 & 6 & 60.2 & 43.6 & 0.66 & -0.66 & 3.6 & 2 \\
\hline 5 & 0.167 & 6 & 61.7 & 48.5 & 0.70 & -0.70 & 4.3 & 2 \\
\hline $6^{a}$ & 0.173 & 6 & 81.8 & - & 1.09 & - & 4.5 & 1 \\
\hline $7^{\mathrm{a}}$ & 0.167 & 6 & 67.8 & 52.5 & 0.80 & -0.57 & 4.0 & 2 \\
\hline $8^{a}$ & 0.167 & 7 & 89.0 & 70.7 & 0.81 & -0.53 & 4.2 & 2 \\
\hline
\end{tabular}

a Tests 6, 7 and 8 were carried out without sand at the bottom.

20-mm sand layer of median grain diameter $D=0.15 \mathrm{~mm}$ and relative density $s=2.65$. The value of $a_{\mathrm{h}}$ has not been chosen lower than $6 \mathrm{~cm}$, as the energy dissipation at the bed due to ripples which form may lead to the vanishing of the pulses when the amplitude of displacement of the oscillating paddle is too weak, as shown in [17].

The bed morphology is obtained using the following image acquisition technique. A vertical light sheet oriented perpendicularly to the longitudinal axis of the flume is generated using a cylindrical lens at the output of an optic fibre in which a laser beam propagates (Fig. 1(b)). This sheet produces a light line on the sandy bed which is video recorded using an immersed pencil camera. This line is parallel to the mean direction of the ripple crests ( $y$-axis) and no information on ripple wavelengths and heights is obtained directly from this line. This differs from the image acquisition technique which has been previously used in other works on bedforms generated by weakly nonlinear waves [6,7], where the vertical light sheet and the recorded light line are oriented parallel to the longitudinal axis of the flume ( $x$-axis). In these previous works, the ripple morphology was deduced directly from the recorded light line which has a limited size, and averaged values of the ripple wavelengths and heights over approximately 10 ripples were obtained. However, the ripple size significantly varies along the flume when solitons are excited in a hydrodynamic 


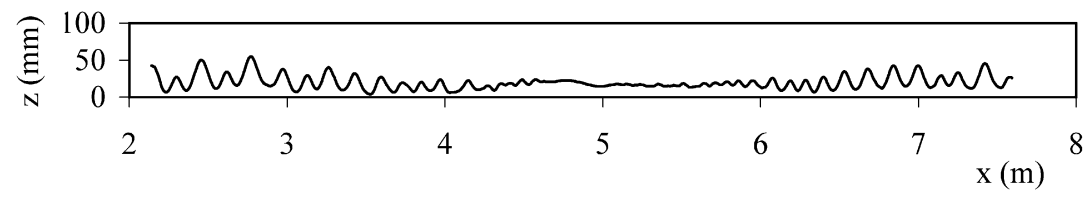

Fig. 2. Variation of the bed level with $x(y=0.25 \mathrm{~m})$. Test $3, t=1.81 \times 10^{5} \mathrm{~s}$ (corresponding to $3.13 \times 10^{4}$ cycles of excitation).

resonator, and the bedforms have to be recorded over much larger areas than for Stokes waves, preventing the use of the methods associated to this type of waves. Jarno-Druaux et al. [7] used also top views of the ripple patterns, but the dimension of the observed domain was limited $(0.28 \mathrm{~m}$ long and $0.22 \mathrm{~m}$ wide). For the present image acquisition technique, the optic fibre and the camera are fixed on a carriage which travels along $5.45 \mathrm{~m}$ of the flume, in the central part, as depicted in Fig. 1(a). The variation with $x$ of the altitude of the interface sand/water is obtained when the flow is at rest; using an adapted image processing technique (Section 2.2), and knowing the velocity of the carriage displacement, the bed morphology and the evolution of the ripple size along the flume can be deduced. This process is carried out regularly during the formation of the bed structures.

Tests 6,7 and 8 were performed without sand at the bottom. Velocity measurements were carried out for Tests 6 and 7 with a two-component, $4 \mathrm{~W}$ argon laser-Doppler anemometer. The measurement volume was $0.14 \mathrm{~mm}^{3}$ and data acquisition was performed at each point during $180 \mathrm{~s}$ with an acquisition frequency of $50 \mathrm{~Hz}$. For these tests, the values of $A_{\mathrm{S} 1}$ and $\varphi_{\mathrm{S} 1}$ are slightly higher than for the corresponding tests (Tests 3 and 5) carried out with sand. This is due to the energy dissipation induced for Tests 3 and 5 by the porosity of the sandy bed and by very small ripples which begin to form during the time required for the pulses to establish in the flume.

\subsection{Image processing technique}

The first step for the image processing technique is to convert the video records into numeric format. This process has been carried out with the ULEAD software, and AVI format files are obtained. The VIRTUAL DUB software is then used to extract images sequences in BMP format from the AVI files. Finally, the images which are in the $(y-z)$ plane are processed using a code developed with the LABVIEW v. 6.1 software. The light intensity distribution of each line composing the images is sampled in 256 values displayed in grey levels. The high light intensity produced at the intersection of the laser plane with the sandy bed can be easily detected, and the bed level on each frame is obtained. This method is carried out for all the images which have been recorded along the flume at a given time $t$; the time $t=0$ corresponds to the beginning of excitation of the surface waves above the initial flat sandy bed. The image pixels and the local positions are related using an object of known dimensions in order to get the horizontal ( $y$-axis) and vertical ( $z$-axis) conversion factors. The distance $x$ between two successively recorded images is obtained from the velocity of the carriage displacement, and from the time interval between these two images. The local ripple lengths and heights can be easily deduced and their variations along the flume at a given time may be considered.

Fig. 2 shows an example of the variation of the bed level with $x$ for Test 3 and $y=0.25 \mathrm{~m}$, that is in the middle width section of the flume. The height $z=0$ is the flume bed level, and $x=0$ corresponds to the position of the wave maker (Fig. 1(a)). It is clear that the ripple size significantly changes along the flume.

The present image processing technique may be used for the study of three-dimensional bed structures such as the brick pattern ripples which can develop in the case of Stokes waves $[18,19]$. For the present tests involving solitons and bound states of solitons, the bed structures were mainly two-dimensional, and the results analysis is focused on the variation with $x$ of the size of the bedforms.

\section{Results}

\subsection{Representation of solitons and bound states of solitons}

In the case of the generation of one pulse propagating in each direction of the flume on the time period of the flow, the shape of this pulse is well represented by the theoretical sech-squared profile $\eta_{\mathrm{S} 1}$ of soliton [16],

$$
\eta_{\mathrm{S} 1}=A_{\mathrm{S} 1} \operatorname{sech}^{2}\left[\sqrt{\frac{3 A_{\mathrm{S} 1}}{4 d^{3}}}\left(x-V_{\mathrm{S} 1} t\right)\right]
$$


(a)

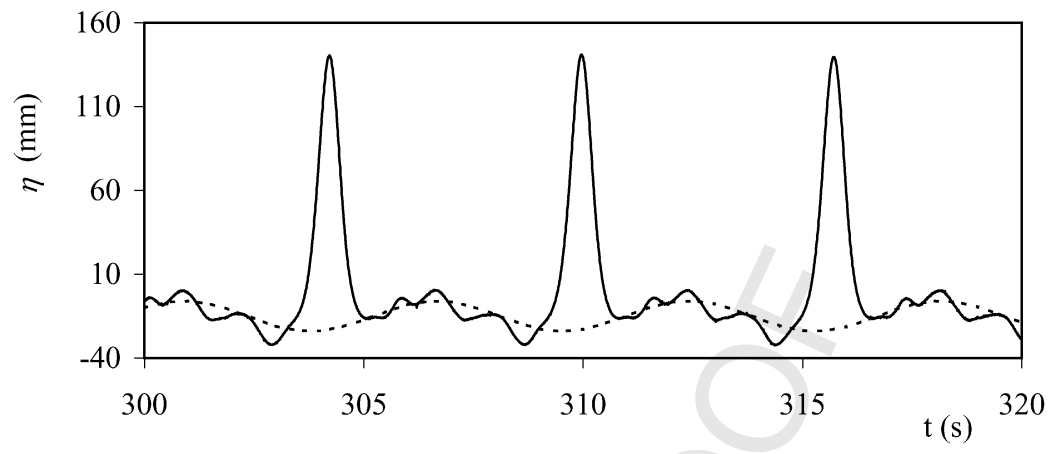

\section{(b) Sequence of solitons and standing harmonic wave (Test 6).}

where $V_{\mathrm{S} 1}$ is the propagation velocity of soliton: $V_{\mathrm{S} 1}=V_{0}\left(1+A_{\mathrm{S} 1} / 2 d\right)$. The profile of the soliton (Eq. (1)) is a solution to the Korteweg-de Vries (KdV) equation which governs the displacement of the free surface $\eta$ in shallow water [20],

$$
\frac{\partial \eta}{\partial t}+V_{0} \frac{\partial \eta}{\partial x}+\frac{3}{2} \frac{V_{0}}{d} \eta \frac{\partial \eta}{\partial x}+\frac{1}{6} V_{0} d^{2} \frac{\partial^{3} \eta}{\partial x^{3}}=0
$$

The KdV equation does not describe the interaction of contra-propagative waves. Neglecting this interaction, the free surface displacement is given by [16]

$$
\eta(x, t)=\eta_{\mathrm{S} 1}\left(x-V_{\mathrm{S} 1} t\right)+\eta_{\mathrm{S} 1}\left(x+V_{\mathrm{S} 1} t\right)+2 A_{0} \cos (k x) \sin \left(\omega t-\varphi_{\mathrm{S} 1}\right)
$$

where $k=2 \pi / L_{\mathrm{h}}$ is the wave number of harmonic waves and $\omega=2 \pi f$. Close to the fixed reflective end of the flume $\left(x=L_{\mathrm{h}}\right)$ where the resistive probe is located, we have

$$
\eta(t)=2 \eta_{\mathrm{S} 1}(t)+2 A_{0} \sin \left(\omega t-\varphi_{\mathrm{S} 1}\right) .
$$

Fig. 3(a) shows the temporal evolution of the free surface elevation measured with the resistive probe for Test 6 when the solitons are established in the flume, that is after about 4 minutes of flow excitation. The standing harmonic wave is extracted from the measured signal using a method described in [16], and the values of $A_{0}, A_{\mathrm{S} 1}$ and $\varphi_{\mathrm{S} 1}$ can be easily deduced, as shown in Fig. 3(b) $\left(\varphi_{\mathrm{S} 1}=\Delta \tau_{\mathrm{S} 1} \omega\right)$.

Let us consider the case of the generation of two pulses on the time period of the flow above a flat bed. By analogy with Eq. (3) and neglecting the interaction of pulses, the free surface displacement may be described by

$$
\eta(x, t)=\eta_{\mathrm{S} 1}\left(x-V_{\mathrm{S} 1} t\right)+\eta_{\mathrm{S} 2}\left[x-V_{\mathrm{S} 2}\left(t-\Delta \tau_{\mathrm{S} 1 \mathrm{~S} 2}\right)\right]+\eta_{\mathrm{S} 1}\left(x+V_{\mathrm{S} 1} t\right)
$$




$$
+\eta_{\mathrm{S} 2}\left[x+V_{\mathrm{S} 2}\left(t-\Delta \tau_{\mathrm{S} 1 \mathrm{~S} 2}\right)\right]+2 A_{0} \cos (k x) \sin \left(\omega t-\varphi_{\mathrm{S} 1}\right)
$$

with

$$
\eta_{\mathrm{S} 2}=A_{\mathrm{S} 2} \operatorname{sech}^{2}\left[\sqrt{\frac{3 A_{\mathrm{S} 2}}{4 d^{3}}}\left(x-V_{\mathrm{S} 2} t\right)\right]
$$

where the terms with subscript 2 refer to the second pulse, and $\Delta \tau_{\mathrm{S} 1 \mathrm{~S} 2}$ is the time interval between the passage of the two pulses $\left(\varphi_{\mathrm{S} 1}-\varphi_{\mathrm{S} 2}=\Delta \tau_{\mathrm{S} 1 \mathrm{~S} 2} \omega\right)$. Close to the fixed end of the flume, Eq. (5) leads to

$$
\eta(t)=2 \eta_{\mathrm{S} 1}(t)+2 \eta_{\mathrm{S} 2}\left(t-\Delta \tau_{\mathrm{S} 1 \mathrm{~S} 2}\right)+2 A_{0} \sin \left(\omega t-\varphi_{\mathrm{S} 1}\right) .
$$

The temporal evolution of the measured free surface elevation $\eta$ is shown for Test 7 in Fig. 4(a) when the flow is just established. The standing harmonic wave is extracted from the measured signal using a similar method to the case of the generation of one pulse on the time period of the flow. Fig. 4(b) shows that the shape of bound states of solitons is very close to sech-squared profiles. The oscillating tail which takes place for the measured free surface elevation in regions where the field amplitude is small is also observed in the case of the excitation of one pulse on the time period of the flow. This tail may result from the collision of contra-propagative pulses. Using high-order approximations in the Boussinesq equation, Byatt-Smyth [21] has shown that soliton collision induces a radiation field that manifests itself as an oscillating tail. The free surface may be described by Eq. (7) when two pulses are generated on the time period of the flow. The values of $A_{\mathrm{S} 1}, A_{\mathrm{S} 2}, \varphi_{\mathrm{S} 1}$ and $\Delta \tau_{\mathrm{S} 1 \mathrm{~S} 2}$ are deduced from the measured signal after extraction of the standing harmonic wave, as depicted in Fig. 4(b).

In the zero-order approximation with respect to nonlinearity, the relationship between the free surface elevation and the horizontal component of fluid velocity $(u)$ in shallow water can be written as

$$
\frac{\partial \eta}{\partial t}+d \frac{\partial u}{\partial x}=0 .
$$

The formulation of the horizontal component of fluid velocity may be obtained from Eqs. (5) and (8):

$$
\begin{aligned}
u= & \frac{1}{d}\left\{V_{\mathrm{S} 1} \eta_{\mathrm{S} 1}\left(x-V_{\mathrm{S} 1} t\right)+V_{\mathrm{S} 2} \eta_{\mathrm{S} 2}\left[x-V_{\mathrm{S} 2}\left(t-\Delta \tau_{\mathrm{S} 1 \mathrm{~S} 2}\right)\right]-V_{\mathrm{S} 1} \eta_{\mathrm{S} 1}\left(x+V_{\mathrm{S} 1} t\right)\right. \\
& \left.-V_{\mathrm{S} 2} \eta_{\mathrm{S} 2}\left[x+V_{\mathrm{S} 2}\left(t-\Delta \tau_{\mathrm{S} 1 \mathrm{~S} 2}\right)\right]-\left(2 A_{0} / k\right) \omega \sin (k x) \cos \left(\omega t-\varphi_{\mathrm{S} 1}\right)\right\} .
\end{aligned}
$$

At the ends of the channel, $k x=0$ or $k x=2 \pi$. In the central part of the channel, $k x=\pi$, and the horizontal component of velocity is equal to zero as the elevations of the contra-propagative waves add up. Solitons propagating in different directions induce velocity pulses of opposite signs. If one soliton is generated on the wave period, two velocity pulses of opposite signs will be observed during this period in the region between the center and the end of the flume, according to Eq. (9). In the case of bound states of solitons, a pair of velocity pulses of different polarity will be observed according to this equation. Such time series were observed in the present tests (see Figs. 7 in Section 3.2). We can note that the vertical component of velocity which has been measured in the present study was approximately two orders of magnitude smaller than the horizontal component of velocity; this indicates that the shallow water approximation is fulfilled to a good accuracy.

The KdV equation takes into consideration disturbances propagating in one direction only. That is why it cannot reproduce all the spatio-temporal properties of the nonlinear waves observed in the hydrodynamic resonator for different parameters of the external forcing. For an explanation of our experimental results, we have made a numerical simulation of one-dimensional Boussinesq equations describing the propagation of waves on shallow water and to which we have added small damping terms:

$$
\begin{aligned}
& \hat{\eta}_{\tau}+\hat{u}_{\xi}+\varepsilon(\hat{u} \hat{\eta})_{\xi}=\frac{1}{6} \mu^{2} \hat{u}_{\xi \xi \xi}+\gamma_{1} \hat{\eta}_{\xi \xi}, \\
& \hat{u}_{\tau}+\hat{\eta}_{\xi}+\varepsilon \hat{u} \hat{u}_{\xi}=\frac{1}{2} \mu^{2} \hat{u}_{\xi \xi \tau}+\gamma_{1} \hat{u}_{\xi \xi} .
\end{aligned}
$$

Details of Eqs. (10) have been described in [16]. Eqs. (10) are written in dimensionless variables, an overcaret denoting dimensionless variables; $\hat{\eta}$ is the displacement of the free surface $\hat{\eta}=\eta / \varepsilon d, \hat{u}$ is the velocity in surface waves $\hat{u}=$ $u / \varepsilon d \omega, \tau$ is the time $\tau=t \omega ; \xi$ is the coordinate along the resonator $\xi=x / L_{\mathrm{e}} ; \mu=d / L_{\mathrm{e}} ; \varepsilon$ is the small parameter of asymptotic expansion. We have supplemented the Boussinesq equations by phenomenological terms describing 
(a)

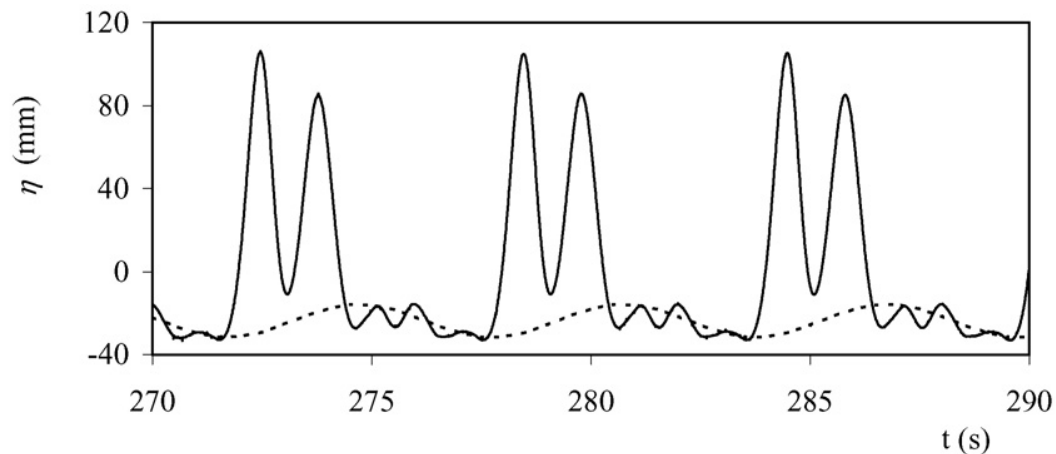

(b)

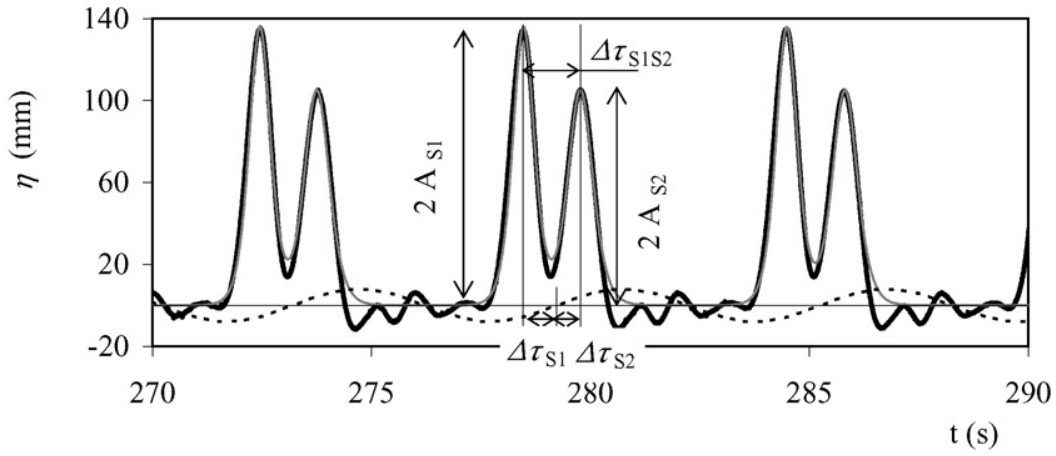

Sequence of bound states of solitons

Sech-squared profiles (from Equation (7), after extraction of the standing harmonic wave)

.... Standing harmonic wave

Fig. 4. (a) Temporal evolution of the free surface and of the extracted standing harmonic wave, close to the reflective end of the flume (Test 7). (b) Sequence of bound states of solitons and standing harmonic wave (Test 7).

dissipation (terms with coefficient $\gamma_{1}$ ). For the numerical calculations we used the following boundary conditions at $\xi=0$ and $\xi=1$ :

$$
\begin{array}{ll}
\frac{\partial \hat{\eta}}{\partial \xi}(\tau, \xi=0)=0, & \hat{u}(\tau, \xi=0)=U_{0} \sin (2 \pi f t), \\
\frac{\partial \hat{\eta}}{\partial \xi}(\tau, \xi=1)=0, & \hat{u}(\tau, \xi=1)=0 .
\end{array}
$$

We have modeled the action of the wavemaker by a periodically varying horizontal velocity at one resonator end. Let us consider results of numerical simulation. The following values of the coefficients have been used: $\gamma_{1}=0.0003$, $\varepsilon=0.25, \mu=0.027, U_{0}=0.92$ (this dimensionless amplitude of external force corresponds to the experimental conditions of Tests 6 and 7), $f / f_{\mathrm{r}}=1.042$ for the generation of one pulse (Test 6 ), and $f / f_{\mathrm{r}}=1.006$ for the generation of two pulses (Test 7). The results for the simulation of Tests 6 and 7 are depicted in the left and right columns of Fig. 5, respectively. Figs. 5(a) and 5(b) show space-time diagrams for the free surface. The temporal evolutions of the free surface at the end of the flume $(\xi=1)$ are presented in Figs. 5(c) and 5(d). The numerical results have good correlations with the experimental data. In particular, the number and the shape of the pulses are well predicted by the numerical simulation (see Figs. 3 and 4 for the experimental temporal evolutions). Figs. 5(e) and 5(f) depict spacetime diagrams for the horizontal component of fluid velocity $u$, and Figs. 5(g) and 5(h) show the temporal evolutions 


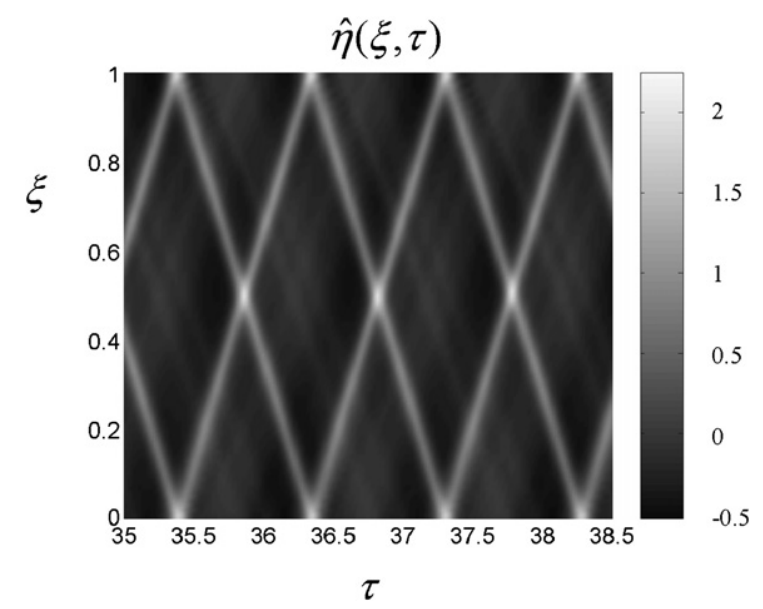

(a)

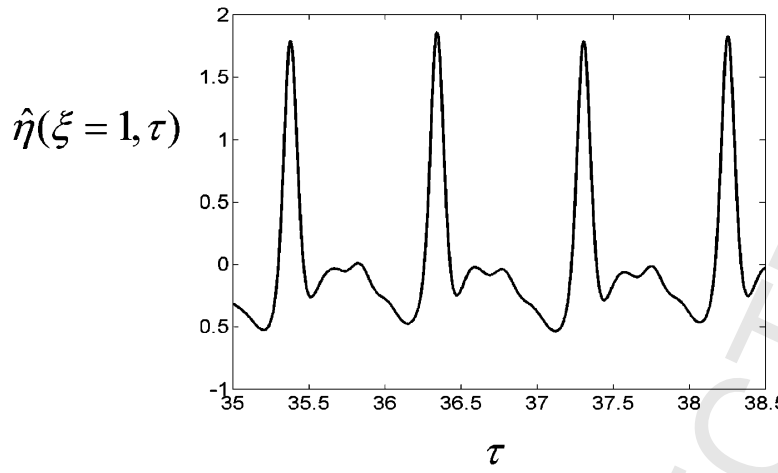

(c)

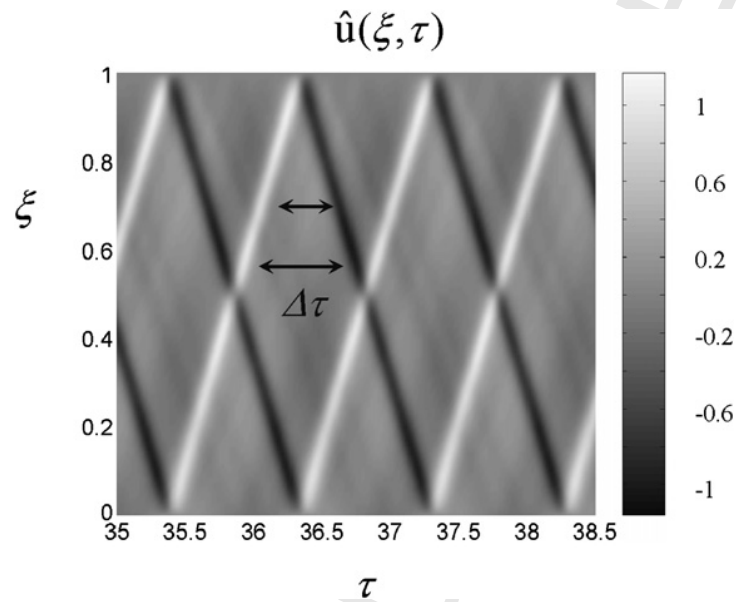

(e)

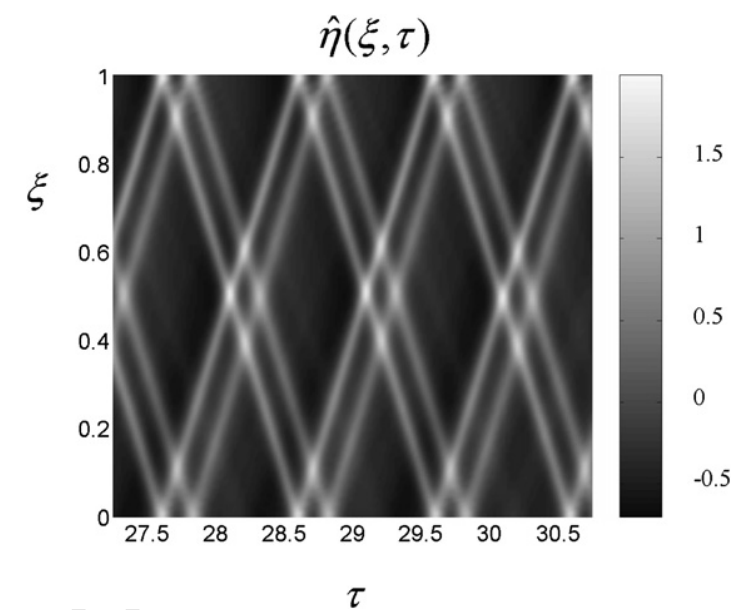

(b)

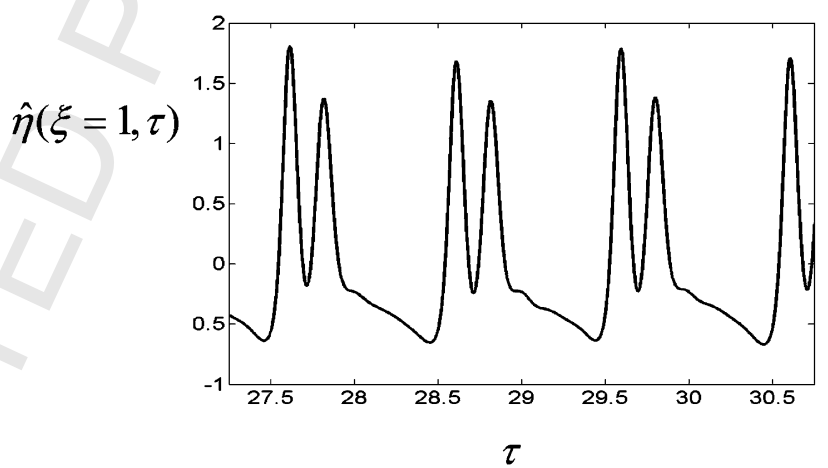

(d)

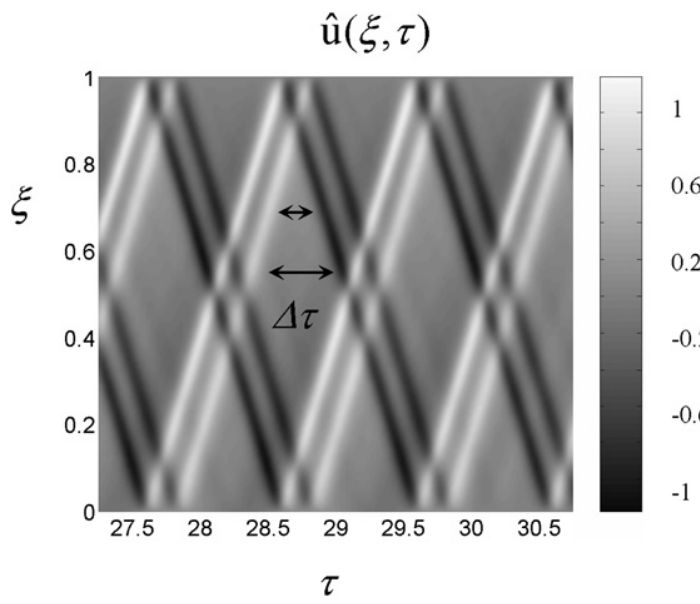

(f)

Fig. 5. Results of numerical simulation of the Boussinesq equations (Eqs. 10) for the experimental conditions of Test 6 (Figs. 5(a), 5(c), 5(e) and 5(g)) and Test 7 (Figs. 5(b), 5(d), 5(f) and 5(h)).

of $u$ for $\xi=0.54$ (this value corresponds to the position of the experimental data shown in Figs. 10). These temporal evolutions are in good agreement with the measured velocities (see Figs. 10 in Section 3.2). 


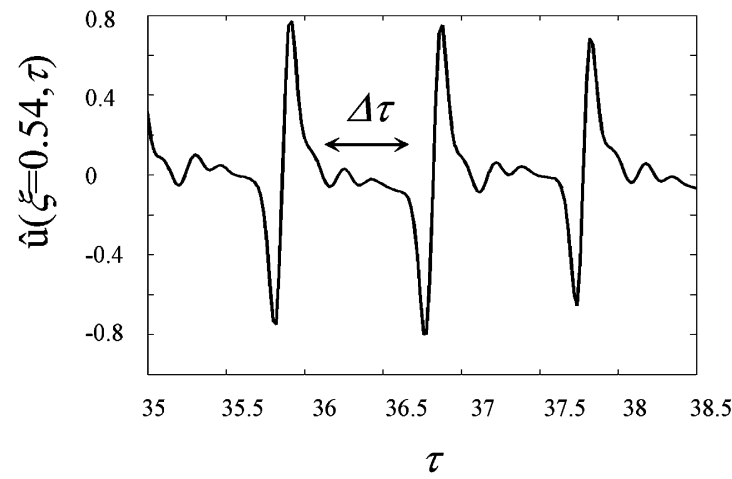

$(\mathrm{g})$

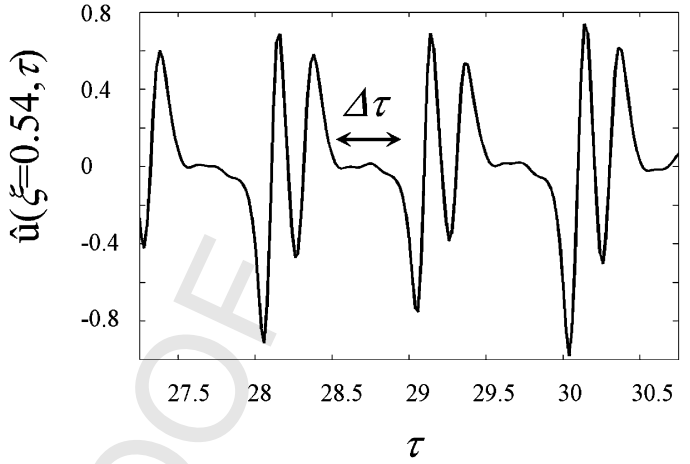

(h)

Fig. 5 (continued).

(a)

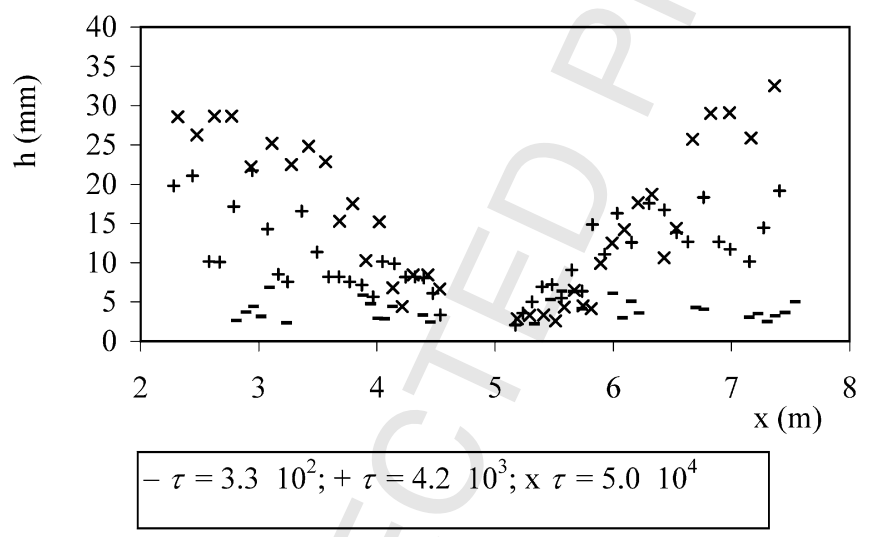

(b)

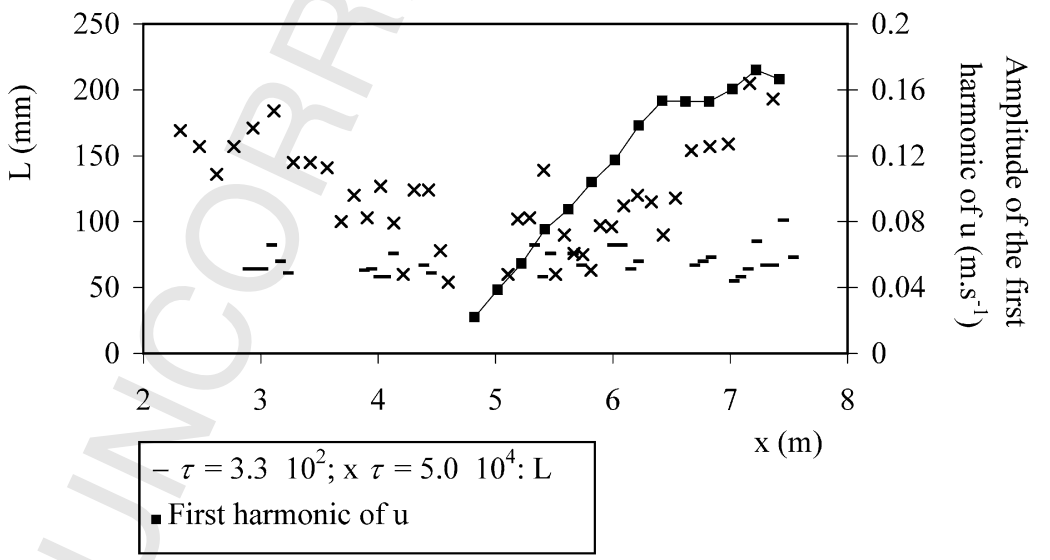

Fig. 6. (a) Variation of the ripple height with $x$ (for $\tau=3.3 \times 10^{2}, 4.2 \times 10^{3}, 5.0 \times 10^{4}$; Test 3). (b) Variation of the ripple wavelength with $x$ (for $\tau=3.3 \times 10^{2}, 5.0 \times 10^{4}$; Test 3), and variation of the amplitude of the first harmonic of $u$ with $x$ (Test $\left.6 ; z=1.5 \mathrm{~mm}\right)$.

\subsection{Ripple formation}

The bed is flat at the beginning of each test. Ripples appear all over the flume after a few minutes of surface wave excitation, except in the central part where the bed remains flat; this region corresponds to the zone of collision of the contra-propagative pulses, and fluid velocities are very small in this region near the bed. Fig. 6(a) shows the 
variation for Test 3 of the ripple height with the distance $x$ from the oscillating paddle, after 52, 675, and 7941 cycles of surface wave excitation, that is when $\tau=3.3 \times 10^{2}, 4.2 \times 10^{3}$, and $5.0 \times 10^{4}$. The ripple height is approximately the same along the flume when the ripples appear $\left(\tau=3.3 \times 10^{2}\right)$. For increasing values of $\tau$, the ripple height $h$ does not significantly change in the vicinity of the central part of the flume $(x=4.82 \mathrm{~m})$ when $h$ strongly increases farther from this part. Similar variations were observed for the ripple wavelength $L$ (Fig. 6(b)). The irregularities in the ripple height and wavelength distributions along the flume result from defects in the ripple pattern; these patterns are never perfectly regular, in flume as in the sea [22]. At $\tau=5.0 \times 10^{4}$, the ripple size does not significantly change any more for increasing values of time all-over the length flume, and we will consider that the ripples have reached their equilibrium state. The ripple size depends on $x$, the horizontal distance from the wave paddle, when solitons are generated in a wave flume used in resonant mode. This is a very significant difference compared with the case of ripples which form beneath 2nd order Stokes waves where the ripple size is approximately constant along the flume.

Velocity measurements were performed with a laser Doppler anemometer for Tests 6 and 7 which were carried out without sand at the bottom. The temporal evolutions of the horizontal $(u)$ and vertical $(v)$ components of fluid velocity just outside the Stokes boundary layer thickness $\delta_{\mathrm{S}}\left(\delta_{\mathrm{S}}=\sqrt{2 v / \omega}=1.4 \mathrm{~mm}\right.$ for Tests 6 and 7 , where $v$ is the kinematic viscosity) are shown in Figs. 7, in the cases of the generation of one (Test 6; Fig. 7(a)) and two pulses (Test 7; Fig. 7(b)) on the time period of the flow, for $x=7.02 \mathrm{~m}$. The vertical component of velocity is very small close to the bed. Positive and negative peaks in the temporal variations of $u$ correspond to the passage of pulses propagating towards the fixed end of the flume and the wave generator, respectively. In the case of the excitation of solitons, one positive peak value and one negative peak value of the horizontal component of velocity are generated on the time period of the flow; in the case of the excitation of bound states of solitons, two positive peak values and two negative peak values of $u$ are present on this time period, the second peak of each sign being slightly smaller than the first one.

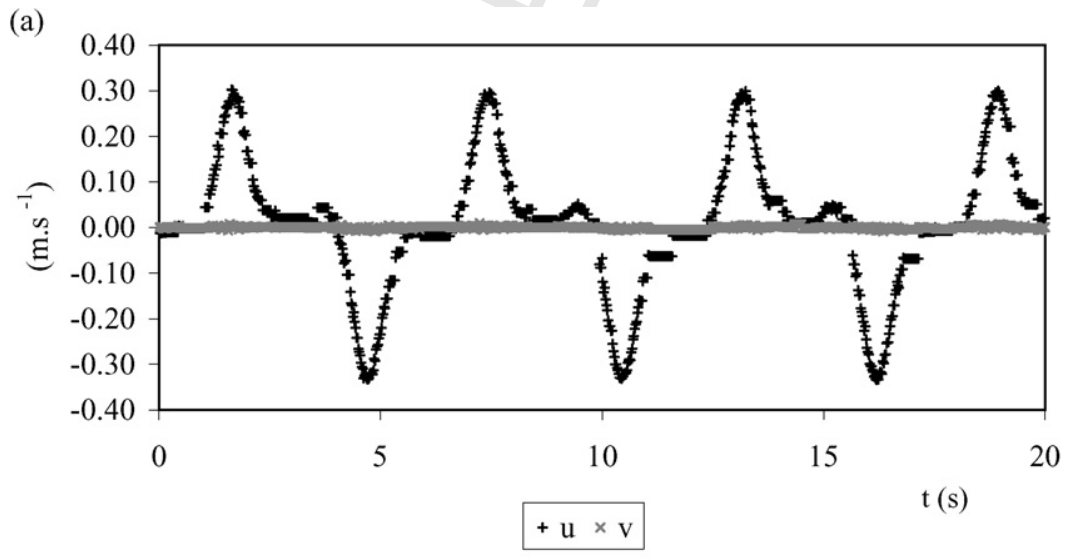

(b)

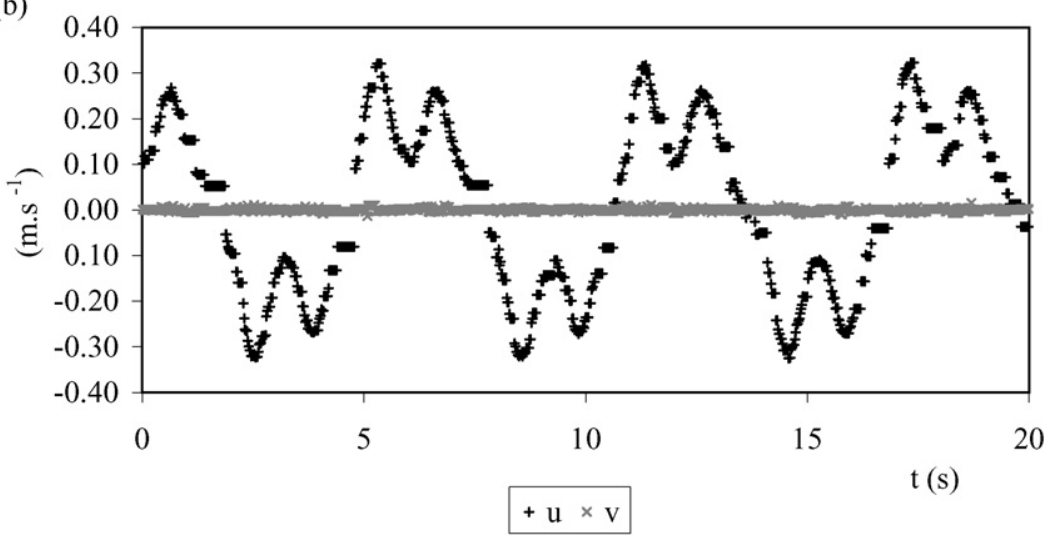


(a)

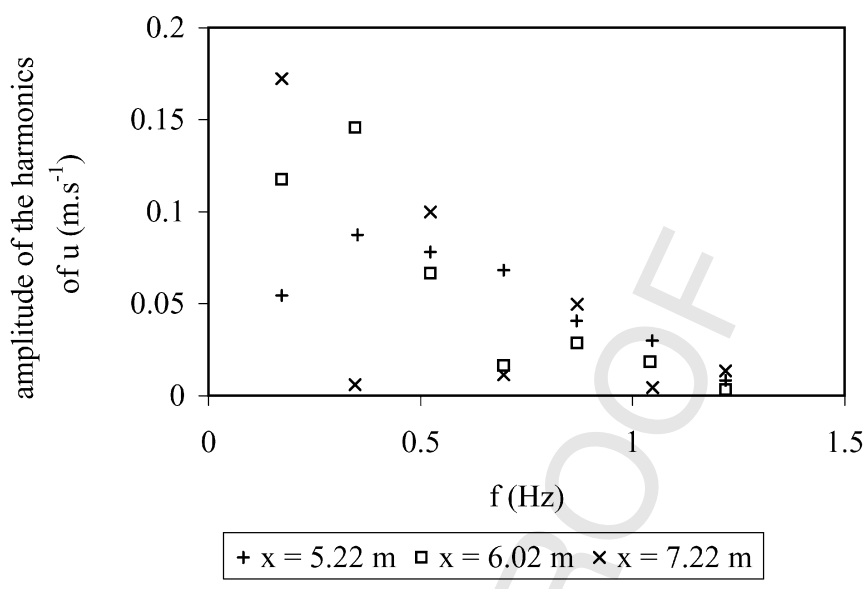

(b)

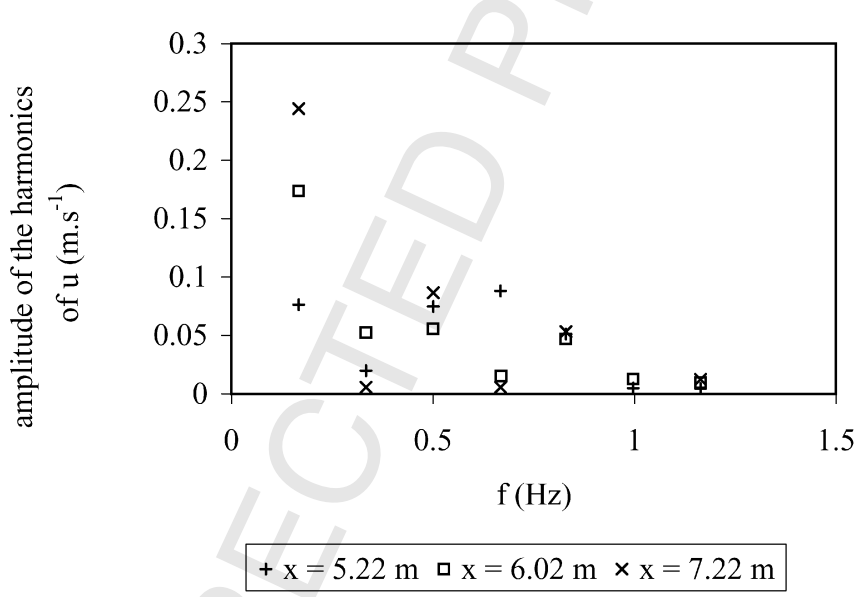

Fig. 8. Amplitude of the harmonics of $u$ for 3 positions along the flume $(x=5.22 \mathrm{~m} ; x=6.02 \mathrm{~m} ; x=7.22 \mathrm{~m} ; z=1.5 \mathrm{~mm}$ ). (a) Test 6 . (b) Test 7 .

The amplitudes of the velocity harmonics close to the bed $(z=1.5 \mathrm{~mm})$, obtained using a FFT algorithm, are shown in Figs. 8 for Tests 6 and 7 for three positions along the flume. These figures show that approximately six velocity harmonics are excited. The variation of the amplitude of the first harmonic with the distance $x$ from the wave paddle is presented in Fig. 9. The velocity measurements were carried out for $4.82 \mathrm{~m} \leqslant x \leqslant 7.42 \mathrm{~m}$, the value $x=4.82 \mathrm{~m}$ corresponding to the flume centre. Velocity measurements could not be carried out for greater values of $x$ since the sidewalls of the flume are not transparent at the ends of the flume. Fig. 9 clearly shows that the amplitude of the first velocity harmonic depends on $x$, in the cases of the excitation of one and two pulses on the time period of the flow. This amplitude increases from the flume centre to the position of the node of the standing harmonic wave positioned at $x=7.22 \mathrm{~m}$ (the nodes of the standing harmonic wave are located at the quarter and at the three quarters of the flume length, that is at $x=2.41 \mathrm{~m}$ and $x=7.22 \mathrm{~m}$ ). The variation of the amplitude of the first velocity harmonic with $x$ is also shown in Fig. 6(b) with the corresponding distribution of ripple length for $\tau=5.0 \times 10^{4}$. It is clear that the variation of the ripple size is linked to the variation of the amplitude of the first velocity harmonic.

Fig. 10(a) shows for Test 6 that the propagation of one pulse towards the wave paddle induces at $x=5.22 \mathrm{~m}$ a negative velocity peak close to the bed, which is directly followed by a positive velocity peak due to the pulse propagating towards the fixed end of the flume. The fluid velocity is then close to zero during a few seconds (the time window $\Delta t$ in Fig. 10(a)), and the sand in suspension can be transported towards the fixed end of the flume, when it did not get time to be transported towards the wave paddle. This process leads to asymmetric ripples (about the crest in cross-section) on each side of the flat bed zone at the central part of the flume. The velocity peaks and the time window $\Delta t$ during which the fluid velocity is close to zero have also been obtained from the numerical simulation (Fig. 5(g) 


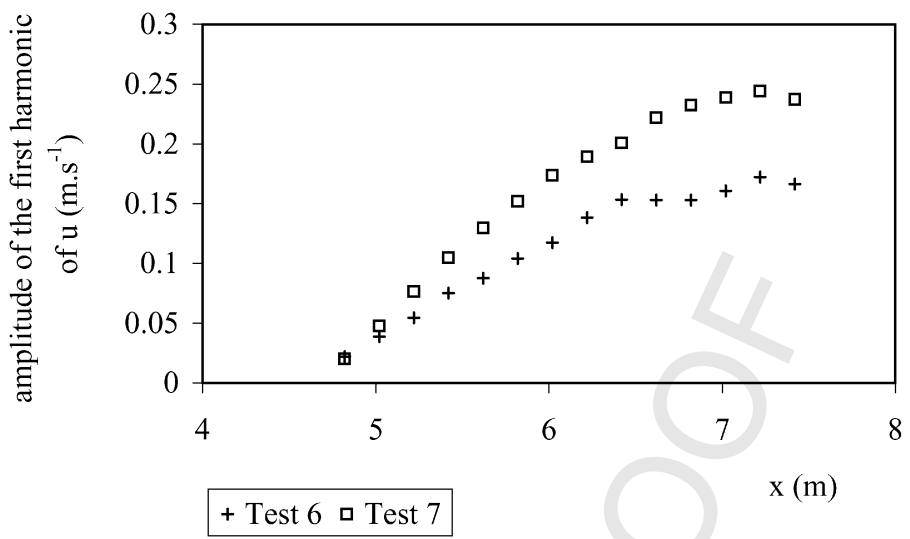

Fig. 9. Variation of the amplitude of the first harmonic of $u$ with $x$ (Tests 6 and $7 ; z=1.5 \mathrm{~mm}$ ).

(a)

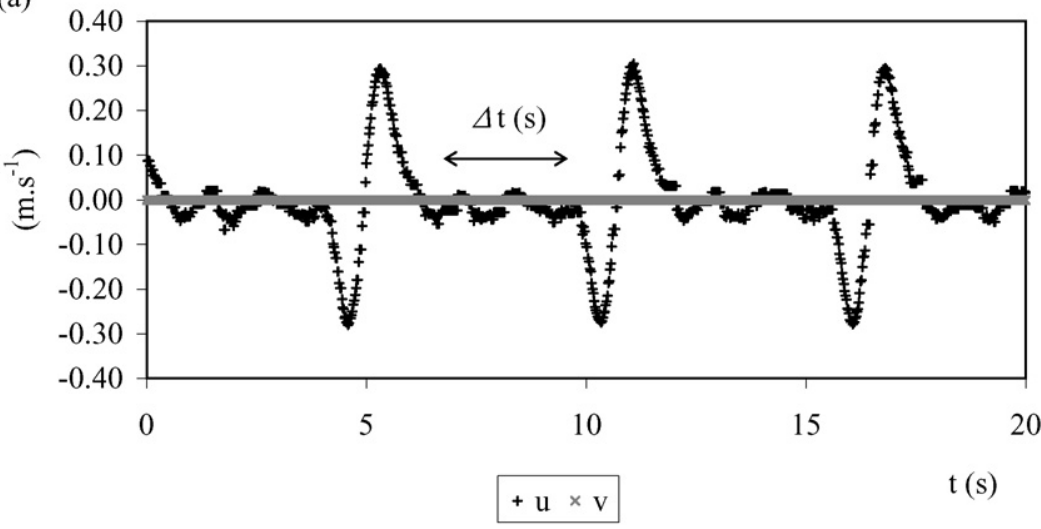

(b)

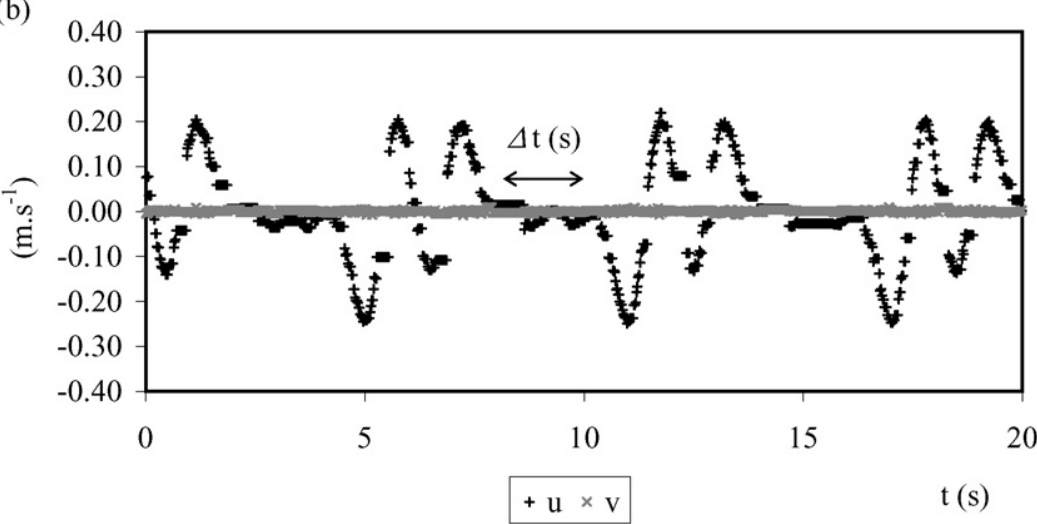

Fig. 10. Temporal evolution of the horizontal ( $u$ ) and vertical ( $v$ ) components of velocity $(x=5.22 \mathrm{~m} ; z=1.5 \mathrm{~mm})$. (a) Test 6 . (b) Test 7 .

where $\Delta \tau=\Delta t \omega)$. Maxworthy [23] has shown that the reflection at a vertical wall of one soliton is equivalent to a collision of two contra-propagative solitons of equal amplitude in an unbounded medium. The same process inducing asymmetric ripples close to the central part of the flume where the contra-propagative solitons collide occurs close to the ends of the flume where the solitons are reflected, and asymmetric ripples are also observed close to the ends of the flume. The space-time diagram for the fluid velocity obtained by numerical simulation and depicted in Fig. 5(e) includes the areas close to the flume ends where velocity measurements could not be carried out; $\xi=0$ or $\xi=1$ 
at the ends of the flume, and $\xi=0.5$ in the central part. Close to the middle of the flume, for values of $\xi$ slightly greater than 0.5 , the time window $\Delta \tau$ during which the fluid velocity is close to zero is large after the passage of positive velocity peaks (bright lines in Fig. 5(e)); an equivalent large time window during which the fluid velocity is close to zero occurs close to the fixed end of the flume $(\xi=1)$ after the passage of negative velocity peaks (dark lines in Fig. 5(e)). In the same way, close to the middle of the flume but for values of $\xi$ slightly smaller than 0.5 , the time window during which the velocity is close to zero is large after the passage of negative velocity peaks, and an equivalent large time window occurs close to the end of the flume for which $\xi=0$, after the positive velocity peaks. Fig. 11 depicts schematically the ripples profiles at the equilibrium state along the flume, presenting the areas where symmetric or asymmetric ripples are observed. These profiles are qualitatively similar in the cases of the excitation of one or two pulses on the time period of the flow. For practical reasons, the ripples profile could not be recorded close to the ends of the flume and the bed morphology was measured along $5.45 \mathrm{~m}$ of the flume (central part, Fig. 11), as mentioned in Section 2.1. The two ends of the recorded area correspond approximately to the places where the ripple size is the highest one along the flume.

The variation with $x$ of the ripple height is shown in Fig. 12 for Test 3 (one pulse on the time period of the flow) and Test 5 (two pulses on the time period of the flow) at the equilibrium state. This state needs less time to be reached when two pulses are generated than when one pulse is generated; this point will be considered in Section 4 . The ripple sizes reach higher values in the case of the excitation of one pulse than in the case of the excitation of two pulses. However, the amplitude of the first velocity harmonic is higher when two pulses are generated, whatever the value of $x$ (Fig. 9). Fig. 7(a) shows for $x=7.02 \mathrm{~m}$ (in the area where the ripples are the largest ones) that when one pulse is excited on the time period of the flow, there is a time window $(\sim 1.5 \mathrm{~s})$ between each velocity peak during which the horizontal component of fluid velocity is close to zero, allowing the sand in suspension close to the bed to be transported successively in each direction of the flume during this time window. When two pulses are excited on the time period of the flow, Fig. 7(b) shows that at the same position there is no time window between the velocity

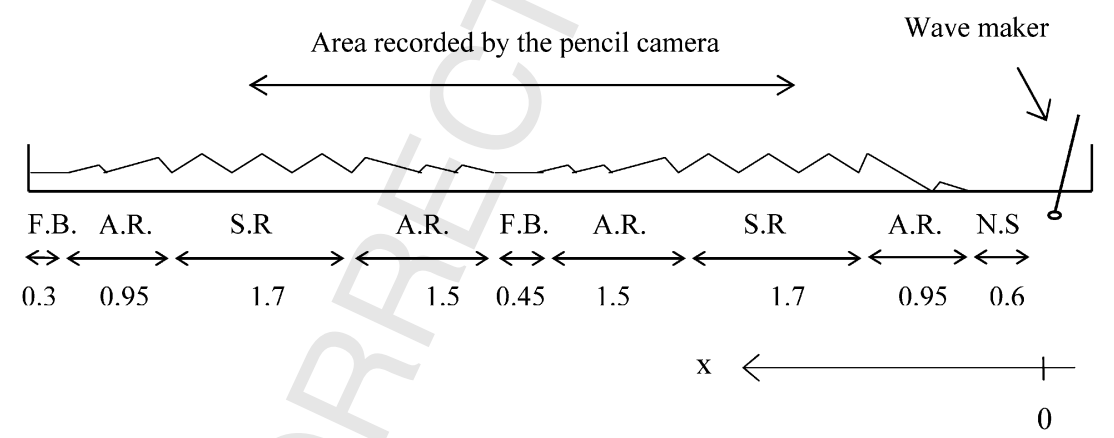

Fig. 11. Sketch showing the areas where symmetric (S.R.) or asymmetric (A.R.) ripples are observed in the flume. F.B.: flat bed; N.S.: no sand. The numbers correspond to the distances (in meters) measured when the ripples have reached the equilibrium state for Test 3.

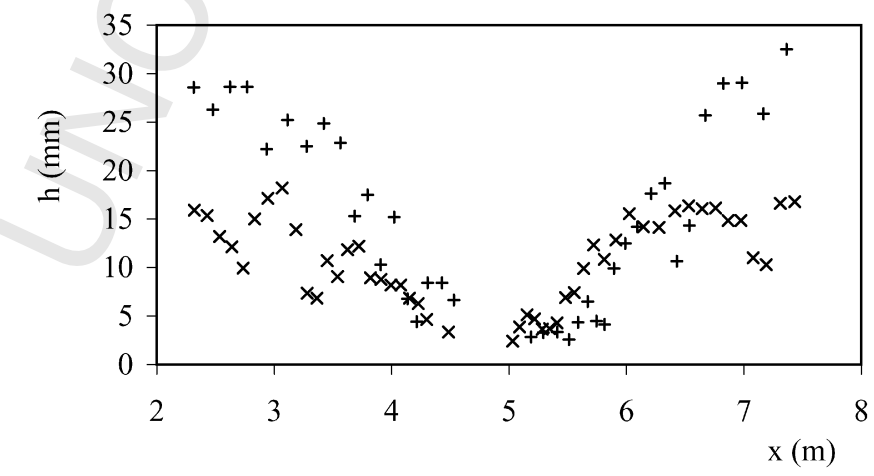

+ Test $3 \times$ Test 5

Fig. 12. Variation of the ripple height with $x$ for Test $3\left(\tau=5.0 \times 10^{4}\right)$ and Test $5\left(\tau=2.0 \times 10^{4}\right)$. 
peaks of opposite sign during which the horizontal component of fluid velocity is close to zero, preventing the sand in suspension to get time to be transported over large distances. The difference of the ripple size between the cases of the generation of one or two pulses on the time period of the flow results in our opinion from this time window.

\subsection{Formation of accretion zones}

Once ripples have reached approximately their equilibrium state, two accretion zones appear progressively beneath the nodes of the standing wave $(x=2.41 \mathrm{~m} ; x=7.22 \mathrm{~m})$, whether one pulse or two pulses are excited on the time period of the flow. The variation of the bed level with $x$ is shown in Fig. 13 for Test 5 and $\tau=2.35 \times 10^{5}$. This variation corresponds to the final bed profile: in the central part of the flume $(4.7 \mathrm{~m}<x<5 \mathrm{~m})$, the mean bed level is approximately the same as at the beginning of the test; on each side of this central part, there is an area, approximately $0.5 \mathrm{~m}$ long, where there is a very thin layer of sand. Further away from the flume centre, the mean bed level progressively increases and the accretion zones take place; the biggest ripples are observed on the top of these accretion zones. Marin et al. [17] qualitatively observed the accretion zones in the case of one pulse on the time period of the flow. In this study, the position of the accretion zones has not been explained, but the authors have shown that this position could not be explained by the Eulerian drift distribution in the flume, which is approximately the same for standing waves alone and for the solitons propagating on the background of a standing harmonic wave. Fig. 10(b) shows that for $x=5.22 \mathrm{~m}$ (just downstream of the flume centre where the solitons collide) and when two pulses are excited on the time period of the flow, the negative velocity peaks are directly followed by positive velocity peaks, preventing the sand in suspension to be transported towards the wave paddle. However, the velocity is close to zero during an approximately $2.5 \mathrm{~s}$ time window after the second positive velocity peak, and the sand in suspension can be transported towards the fixed end of the flume. This time window $\Delta t$ varies with the distance $x$ along the flume, as shown in Fig. 14 for $5 \mathrm{~m}<\mathrm{x}<7.5 \mathrm{~m}$. Using the results of the numerical simulation described in Section 3.1, it is easy to obtain the dependence of the time window $\Delta t$ on the coordinate $x$ along the flume; these numerical results are also presented in Fig. 14. For the numerical estimation, the time window has been determined as the time interval occurring after the second positive velocity peak (after the positive velocity peak in the case of the excitation of one pulse) and during which $0.1 u_{\min }<u<0.1 u_{\max }$, where $u_{\min }$ and $u_{\max }$ are the minimum and the maximum values of $\mathrm{u}$

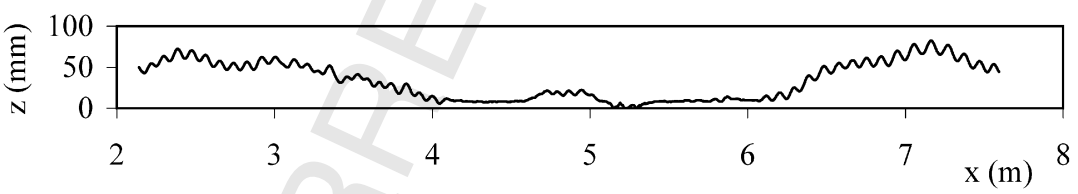

Fig. 13. Variation of the bed level with $x(y=0.25 \mathrm{~m})$ for Test 5 and $\tau=2.35 \times 10^{5}$.

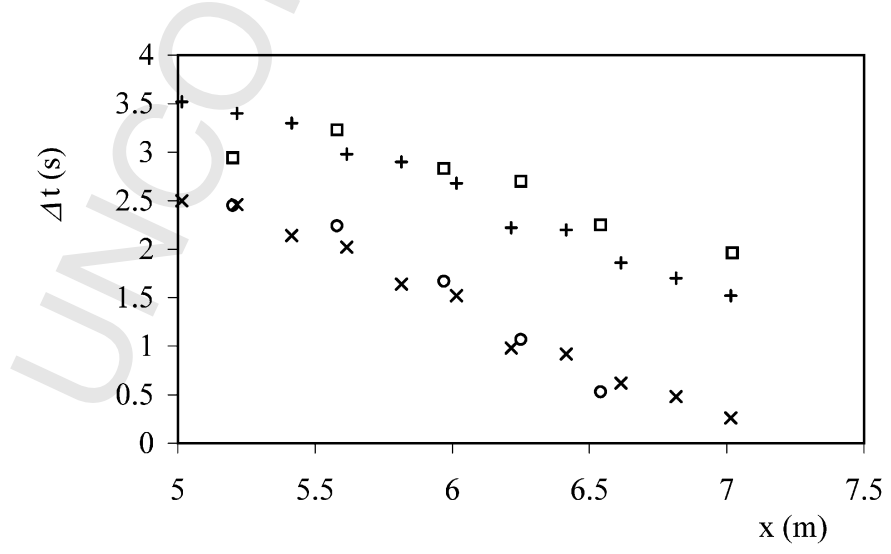

+ Test 6, Experimental results a Test 6, Numerical results

$\times$ Test 7 , Experimental results $\circ$ Test 7 , Numerical results

Fig. 14. Variation of the time window $\Delta t$ with $x$ for Tests 6 and 7 (experimental and numerical results). 
during the wave period, respectively. The time window $\Delta \tau=\Delta t \omega$ is depicted in Figs. 5(e) and 5(f) for two values of $\xi=x / L_{\mathrm{e}}$. Fig. 14 shows that the experimental results are in good agreement with the numerical results. The reflection of solitons at a vertical wall being equivalent to a collision of two contra-propagative solitons, the same process occurs close to the fixed end of the flume as close to the flume centre, inducing the transport of sediments in suspension from the fixed end towards the flume centre. The combined effect of sand transport from the flume centre towards the fixed end of the flume, and from this end of the flume towards the flume centre results in a sand accumulation at the three fourth of the flume length, centred close to $x=7.2 \mathrm{~m}$. The accretion zone upstream of the middle of the flume, centred close to $x=2.4 \mathrm{~m}$, is generated in the same way. The variation of the time window between the passage of the contrapropagative pulses with $x$ leads to the accretion zones. The same process takes place in the case of the excitation of one pulse on the time period of the flow (the variation of $\Delta t$ with $x$ is also shown for Test 6 in Fig. 14).

\section{Discussion}

We have performed a spatial average of the recorded ripple heights and wavelengths, at each time for which the ripple sizes were measured, in order to study the ripples temporal growth. Fig. 15 shows the variation of the spatial mean value of the dimensionless ripple height $\bar{h} / \overline{h_{\mathrm{eq}}}$, where $\bar{h}$ is the spatial mean ripple height and $\overline{h_{\mathrm{eq}}}$ the final value of $\bar{h}$, with the dimensionless time $\tau$. A similar variation is observed for the dimensionless ripple lengths (not shown). Let us consider the following equation for the description of ripple growth:

$$
\frac{\mathrm{d} \bar{h}}{\mathrm{~d} t}=\alpha_{1} E_{\mathrm{S}}-\alpha_{2} \bar{h}
$$

In this equation, $\alpha_{1}$ and $\alpha_{2}$ are phenomenological coefficients. The first term in the right side of Eq. (12) describes the ripple growth due to the external force. The second term of this equation corresponds to the saturation of the ripple growth. Eq. (12) may be integrated to yield

$$
\bar{h}=\frac{\alpha_{1}}{\alpha_{2}} E_{\mathrm{S}}\left[1-\exp \left(-\alpha_{2} t\right)\right]
$$

assuming that $\bar{h}=0$ when $t=0$ and that the soliton energy is constant. For $t \rightarrow \infty, \bar{h} \rightarrow \overline{h_{\mathrm{eq}}}=\frac{\alpha_{1}}{\alpha_{2}} E_{\mathrm{S}}$, and Eq. (13) may be written in the following form

$$
\frac{\bar{h}}{\overline{\overline{h_{\mathrm{eq}}}}}=1-\exp \left(-\alpha_{2} t\right)=1-\exp \left(-\frac{\alpha_{2}}{\omega} \tau\right) .
$$

Fig. 15 shows that this equation which is analogous to the exponential law for the ripple growth under Stokes waves [7] can apply to solitons and bound states of solitons. This figure also shows that the equilibrium state is reached more rapidly in the case of the excitation of two pulses (Test 5) than in the case of the excitation of one pulse (Test 3 ).

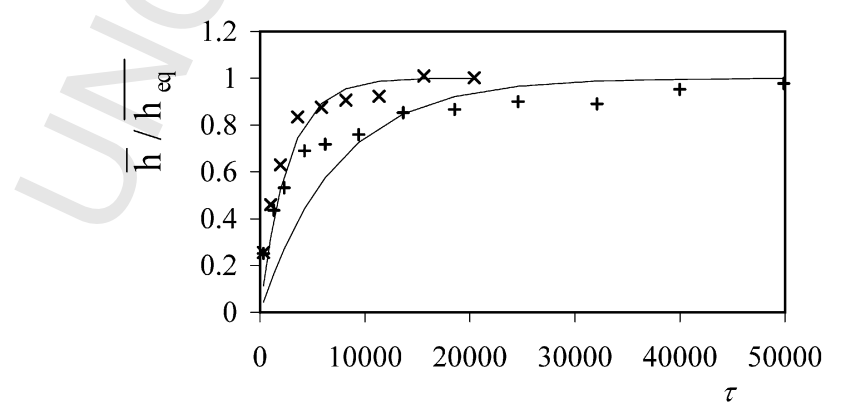

+ Test $3 \times$ Test $5-$ Equation (14)

Fig. 15. Comparison between experimental and theoretical (Eqs. (14) and (16)) values of $\bar{h} / \overline{h_{\mathrm{eq}}}$ (Tests 3 and 5). 
It has been pointed out in the previous section that the amplitude of the first velocity harmonic depends on $x$, and that the value of this amplitude is maximal at the node of the standing harmonic wave. Let us consider the mobility number $\psi$ defined by

$$
\psi=\frac{U_{1 \max }^{2}}{g(s-1) D}
$$

where $U_{1 \max }$ is the maximal value of the amplitude of the first velocity harmonic just outside the Stokes boundary layer thickness. The coefficient $\alpha_{2}$ may be estimated from the present data involving one or two pulses on the time period of the flow by

$$
\alpha_{2}=\frac{\omega \psi^{3 / 2}}{3.1 \times 10^{5}} .
$$

This coefficient which is connected to the time of ripple formation may be defined in a dimensionless way by:

$$
\alpha_{2}^{\prime}=\frac{\alpha_{2}}{\omega}=\frac{\psi^{3 / 2}}{3.1 \times 10^{5}}
$$

The ripple height $\bar{h}$ reaches $95 \%$ of its equilibrium value when $t=t_{\mathrm{eq}}=3 / \alpha_{2}$ (Eq. (14)). The time $t_{\mathrm{eq}}$ may be considered as the time necessary to reach the equilibrium state. This gives numbers of cycles of approximately 3500 and 1300 for the ripples to reach their equilibrium size, in the cases of the excitation of one and two pulses on the time period of the flow, respectively. Jarno-Druaux et al. [7] studied the ripples formation in the case of 2nd order Stokes waves in the same wave flume as for present tests. In the range 3 to 15 for the mobility numbers considered in this previous study, the number of cycles necessary to reach the bed equilibrium state was found to be about 700 cycles for the lowest $\psi$ values, and about 300 cycles for the highest ones. For the present tests involving the excitation of one pulse on the time period of the flow, the values of the mobility number (defined by Eq. (15)) lie in the range 10 to 15. It is clear that the time scale of the ripple formation is much greater in the case of the excitation of one pulse on the time period of the flow than for second order Stokes waves. For the present tests involving the excitation of two pulses on the time period of the flow, the values of $\psi$ lie in the range 20 to 25 , and the number of cycles necessary for the ripples to reach their equilibrium size is significantly larger than for Stokes waves, despite higher values of $\psi$. The pulsating nature of the flow in the case of solitons (and bound states of solitons) clearly increases the time of ripple formation. In the case of the ripple growth under Stokes waves, the coefficient corresponding to $\alpha_{2}$ in the present paper involves a $1 / 2$ power law dependency between this coefficient and the mobility number [7], when the present formulation obtained using a best-fit procedure involves a 3/2 power law (Eq. (16)). This results from a much higher dependence of the time necessary for the ripples to reach their equilibrium state on the mobility number under solitons and bound states of solitons than under Stokes waves.

\section{Conclusions}

A laboratory study has been carried out on the formation of sand bedforms under solitons and bound states of solitons excited in a wave flume on the background of a standing harmonic wave. One or two pulses propagate in each direction of the flume on the time period of the flow when solitons or bound states of solitons are generated, respectively. An original experimental method based on image processing has been developed to obtain the morphology of the sandy bed over large areas. The size and the shape of ripples which form on the bed significantly change from one end of the flume to the other end. In particular, present tests show that the ripple profiles are symmetrical about the crest in cross-section in some areas of the flume, and asymmetrical in other areas. The variation of the ripple size along the flume results from the variation of the amplitude of the first harmonic of the horizontal component of fluid velocity close to the bed with the horizontal distance $x$ from the wave paddle. The symmetrical or asymmetrical shape of the ripples depends on the difference of the time window $\Delta t$ during which the velocity is close to zero in the vicinity of the bed after the passage of the pulses, whether they propagate towards the wave paddle or towards the fixed reflective end of the flume. Symmetrical ripples are found in the areas where this difference is negligible. The variation of the time window $\Delta t$ with $x$ induces accretion zones which appear progressively beneath the nodes of the standing wave. A numerical simulation of Boussinesq equations shows a good correlation between the measured and calculated values of $\Delta t$. The temporal growth of the spatially averaged ripple size is described by an equation 
obtained from a phenomenological analysis, which defines a coefficient connected to the time of ripple formation under solitons and bound states of solitons.

\section{References}

[1] R.A. Bagnold, Motion of waves in shallow water: Interaction of waves and sand bottoms, Proc. Roy. Soc. London Ser. A 187 (1946) 1-15.

[2] J.F.A. Sleath, On rolling-grain ripples, J. Hydraul. Res. 14 (1976) 69-81.

[3] P. Blondeaux, Sand ripples under sea waves: Part 1. Ripple formation, J. Fluid Mech. 218 (1990) 1-17.

[4] G. Vittori, P. Blondeaux, Sand ripples under sea waves: Part 2. Finite-amplitude development, J. Fluid Mech. 218 (1990) 19-39.

[5] P. Blondeaux, E. Foti, G. Vittori, Migrating sea ripples, Eur. J. Mech. B Fluids 19 (2000) 285-301.

[6] C. Faraci, E. Foti, Geometry, migration and evolution of small-scale bedforms generated by regular and irregular waves, Coast. Engrg. 47 (2002) 35-52.

[7] A. Jarno-Druaux, J. Brossard, F. Marin, Dynamical evolution of ripples in a wave channel, Eur. J. Mech. B Fluids 23 (2004) $695-708$.

[8] P.L.-F. Liu, C.E. Synolakis, H.H. Yeh, Report on the international workshop on long-wave run-up, J. Fluid Mech. 229 (1991) $675-688$.

[9] F. Dias, D. Dutykh, Dynamics of Tsunami Waves, Springer, 2006, 25 pp.

[10] W.H. Munk, The solitary wave theory and its application to surf problems, Ann. N.Y. Acad. Sci. 51 (1949) $376-423$.

[11] J. Boussinesq, Theorie de l'intumescence liquide appelee onde solitaire ou de translation se propageant dans un canal rectangulaire, Comptes Rendus Acad. Sci. 72 (1871) 755-759.

[12] D.J. Korteweg, G. de Vries, On the change of form of long waves advancing in a rectangular channel, and on a new type of long stationary waves, Philos. Mag. 39 (5) (1895) 442-443.

[13] J.S. Russell, Report of the committee on waves, in: J. Murray (Ed.), Report of the 7th Meeting of the British Association for the Advancement of Science, London, 1838, pp. 417-496.

[14] J.S. Russell, Report on waves, in: J. Murray (Ed.), Report of the 14th Meeting of the British Association for the Advancement of Science, London, 1844, pp. 311-390.

[15] A.B. Ezersky, O.E. Poloukhina, J. Brossard, F. Marin, I. Mutabazi, Modélisation des ondes solitaires excitées dans un canal en eau peu profonde, in: 16th Congrès Français de Mécanique, Nice, 2003, on CD.

[16] A.B. Ezersky, O.E. Poloukhina, J. Brossard, F. Marin, I. Mutabazi, Spatiotemporal properties of solitons excited on the surface of shallow water in a hydrodynamic resonator, Phys. Fluids 18 (6) (2006) 067104.

[17] F. Marin, N. Abcha, J. Brossard, A.B. Ezersky, Laboratory study of sand bed forms induced by solitary waves in shallow water, J. Geophys. Res. 110 (F4) (2005) F04S17.

[18] G. Vittori, P. Blondeaux, Sand ripples under sea waves: Part 3. Brick-pattern ripple formation, J. Fluid Mech. 239 (1992) $23-45$.

[19] J.F.A. Sleath, Sea Bed Mechanics, J. Wiley, Hoboken, 1984.

[20] M. Remoissenet, Waves Calles Solitons: Concepts and Experiments, third ed., Springer, New York, 1996.

[21] J.G.B. Byatt-Smyth, The reflection of a solitary wave by a vertical wall, J. Fluid Mech. 197 (1988) 503-521.

[22] D.M. Hanes, V. Alymov, Y.S. Chang, Wave-formed sand ripples at Duck, North Carolina, J. Geophys. Res. 106 (C10) (2001) $22575-22592$.

[23] T. Maxworthy, Experiments on collision between solitary waves, J. Fluid Mech. 76 (1976) 177-185. 